\title{
Alternanza scuola-lavoro (work-based learning) as a resource for higher education ${ }^{1}$
}

\section{Cristina Lisimberti, Katia Montalbetti}

Faculty of Education, Università Cattolica del Sacro Cuore, Italy.

\begin{abstract}
In Italy, Law no. 107/2015 made obligatory for all second grade secondary school students to spend a certain number of hours on alternanza scuolalavoro activities (work-based learning). For Italian schools this opened up new horizons as well as new challenges on multiple levels: organisational, didactic and educational. Anyway Legal provisions and scientific evidence are in fact not sufficient to guarantee quality because school and work contexts are systems guided by different motivations, models and mechanisms.

"Tailoring" and "co-designing" are the main characteristics of alternanza programmes offered by Università Cattolica del Sacro Cuore; to investigate the quality of these experiences a survey has been launched.

Whilst the study confirms the satisfaction of the participating schools, from the perspective of ongoing improvement, a number of areas for development emerged in relation to evaluation issue in particular.

Beyond the experience itself, universities should consider alternanza a major topic for consideration, since it enhances their fundamental activities: research, education and the third mission; accommodating students on alternanza programmes is therefore a means of responding to local needs but also an opportunity to consolidate university development strategies.
\end{abstract}

Keywords: Alternanza (work-based learning); Assessment; University; Research.

\footnotetext{
${ }^{1}$ Katia Montalbetti wrote the paragraph n.1 and Cristina Lisimberti the paragraph n.3. The paragraph n. 2 was written together.
} 


\section{Alternanza scuola-lavoro (work-based learning) in the Italian context}

The issue of the link between school education and the world of work has been widely developed in recent decades, and increasingly challenged by the difficulties facing the national and supranational economy (Vecchiarelli, 2015). In Italy, Law no. 107/2015 completed a process, not entirely without difficulty, of progressively integrating on-the-job education into school curricula (Gentili, 2016). In the academic year 2015/16, this law made it obligatory for all second grade secondary school students to spend, over the course of three years ${ }^{2}$, a certain number of hours (depending on the subject ${ }^{3}$ ) on alternanza scuolalavoro activities. For Italian schools, particularly those not directly geared towards preparing students for work and with a less developed tradition of apprenticeships and placements, this opened up new horizons as well as new challenges on multiple levels: organisational, didactic and educational (Torre, 2016, 2017; Crivellari, 2018). These changes not only affected the way schools were run internally, but also brought to the fore their relationships with the local area in terms of mutual enhancement (Fedeli, Tino, 2018).

In the literature, international studies conducted on experiences of Work-Based Learning (WBL) and Work-Related Learning (WRL) (Gibbs \& Armsby, 2010; Bertagna, 2013; Dalrymple, Kemp \& Smith, 2014; Schaap, Baartman \& de Bruijn, 2012; Akkerman \& Bakker, 2012; Flynn, Pillay \& Watters, 2016; Fabbri, Melacarne \& Allodola, 2015) have widely acknowledged the educational and training value of work contexts (Wesselink, De Jong \& Biemans, 2010). Nevertheless, legal provisions and scientific evidence do not guarantee quality alternanza programmes. In fact, the two systems in question are guided by different motivations, models and mechanisms: it is, therefore, essential that they gain mutual knowledge and understanding and learn to collaborate (Cuppini, 2018).

Unlike previous placement or apprenticeship activities, alternanza activities take place within a single school-run training project (Nicoli \& Salatin, 2018). The school must plan, implement, monitor and assess the programmes based on special agreements with the hosting organisations. In this sense, alternanza scuola-lavoro is designed as the extension of school-based learning activities outside the class room in real contexts (Sicurello, 2016), which must be properly prepared to accommodate students in order for the experience to succeed (Sappa, Choy \& Aprea, 2016).

On the one hand, schools must learn to "look further" and, on the other, companies/institutions must be prepared to engage with students beyond the formal level, offering them the opportunity to participate in authentic experiences. The potential of

\footnotetext{
2 Students from 16 to 18 .

${ }^{3}$ In the three-year period, 200 hours (high schools) and 400 hours (technical and professional institutes) untill a.s. 2017/2018.
} 
alternanza is not limited to professionalization, but has a particular educational impact too, in that it aims to develop students' self-awareness so that they can plan their own future based on a realistic interpretation of the world.

For universities, therefore, accommodating students on alternanza programmes is a means of responding to local needs and demand but also an opportunity to consolidate their own guidance strategies. This two-fold perspective (Montalbetti, 2018; Loiodice et al., 2018) forms the backdrop to the experiences in a private Italian university described over the following pages.

\section{Alternanza at the Università Cattolica del Sacro Cuore}

\subsection{The Structure of the model}

Università Cattolica del Sacro Cuore (UCSC) has received students as a participant in the alternanza scuola-lavoro scheme since the latter was introduced into schools in 2015/16. The activities are becoming more established over time: during the last three years in question (2015/16-17/18), the participating number of schools and students grew to 53 schools (nearly all licei secondary schools) and 412 students in the last school year (2017/18) involving humanistic and scientific faculties.

For UCSC, alternanza scuola-lavoro is an opportunity to meet and engage with local secondary schools, students and teachers in a relationship that extends beyond the organisational dimension, being based on the recognition of this experience as a valuable source of guidance. Indeed, participating schools become part of a network enabling them to enhance the opportunities the students receive by continually collaborating with the University and co-designing the activities and itineraries. As well as on an educational level, students are also offered opportunities for development on a personal level in the form of a continual relationship with the Ufficio Orientamento (student guidance office), which remains an important contact even after the end of the course, helping students develop a personal plan for approaching university and the professional world.

Therefore, the "tailoring" and "co-designing" of the itineraries are two key concepts integral to the offering. All courses are the product of collaboration between the Ufficio Orientamento and the schools involved, and take into consideration the requests, interests, aspirations and potential of each individual.

On an organisational level, the offering is considerably varied: individual projects aimed at individual students or projects designed for groups of students from the same school of varied duration (20-120 hours over the course of the year). 
Moreover, activities may be conducted in collaboration with the staff lecturer ("projects"), or within the administrative structures and various services of the University e.g. offices, management offices or libraries ("pathways”).

Given the investment made by the university in the sector and the innovativeness of the offering, over time it became desirable to monitor and evaluate the activities in order to continually increase the quality of the provision and identify any necessary improvements in a timely fashion.

\subsection{Description of the methodology}

The desire to investigate the quality of the experiences at the University launched a joint study by CeRiForm (Centre for Studies and Research on Education Policy) and the Ufficio Orientamento, surveying the perceptions of the schools involved.

The report will focus on the alternanza scuola-lavoro activities held at the Milan campus during the academic year 2017/18. In particular, from the distribution of an on-line questionnaire (June-July 2018) to the contact teachers in each school, information was collected in the following areas:

- $\quad$ Quality of the experience (planning, organisation and outcome)

- The usefulness, effectiveness and sustainability of the collaboration between the University and schools in co-designing the programme

- $\quad$ Student satisfaction

- $\quad$ Strong and weak points to emerge from the evaluation phase

These dimensions were investigated using a four-level scale: very positive $(++)$, positive $(+)$, negative $(-)$, very negative (--).

The valid questionnaires represent 44 out of the 53 schools participating in the projects/pathways, or $83 \%$. Below are some of the key findings to emerge from the survey.

\subsection{Presentation of the data}

The schools that completed the questionnaire had mostly participated in projects with the direct involvement of university lecturers ("projects" 61\%), around a third had been involved in the pathways in administrative departments ("pathways” 30\%), whilst a small number (9\%) had participated in both.

The number of participating students from each school varies somewhat, but is generally limited. In just over a quarter of cases (27\%) only 1 or 2 students participated per school; 39 students in $23 \%$ of cases; $10-19$ in $20 \%$ of cases and 20 or more in $30 \%$ of remaining cases. The limited number of students is a positive indicator, confirming the choice to encourage the tailoring of activities and make it possible to provide each student with 
individual support. Nevertheless, for individual schools, this decision has the onerous implication of forcing them to collaborate with numerous institutions.

On a general level, the experiences are widely appreciated (fig. 1), as demonstrated by the nearly exclusive allocation of positive levels on the scale. Schools are either very satisfied $(++70.4 \%)$ or satisfied $(+27.3 \%)$ with the organisation, planning $(++65.9 \%$; $+34.1 \%)$ and educational impact on students (++63.6\%; +36.4\%).

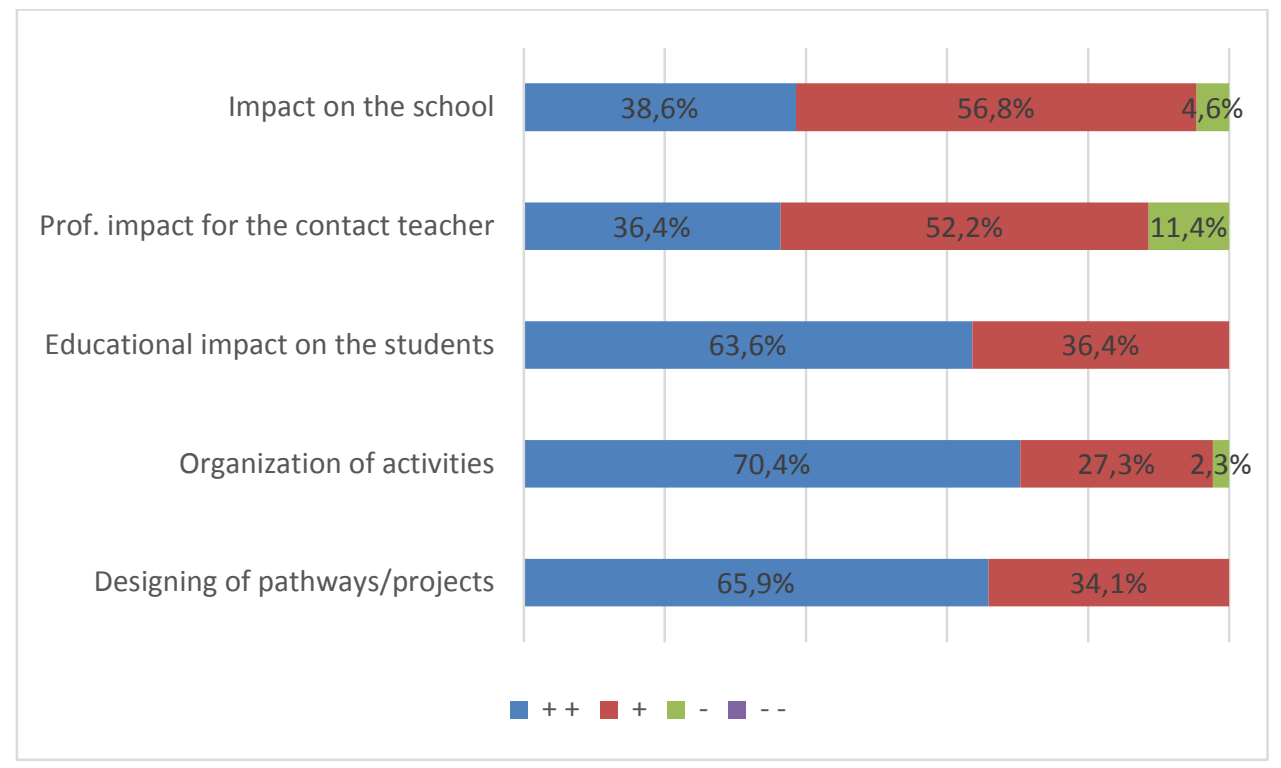

Figure 1. The quality of the experience.

The decision to co-construct the pathways/projects is seen as particularly favourable by schools (fig. 2). In particular, there is distinct recognition of value in terms of usefulness (++ 68.2\%; + 31.8\%), effectiveness (++ 61.4\%; + 34.1\%; - 4.5\%) and, to a lesser degree, sustainability (++ 42.2\%; + 52.3\%; - 4.5\%). Given the limited number of students participating in ASL at UCSC, it is clear that schools appreciate the decision to engage each individual student in designing their pathway/project, acknowledging the educational value whilst also noting the complexity and labour-intensive nature of this approach.

Most schools surveyed student satisfaction (41 out of 44) with significant results (fig. 3): schools report that students say they are very satisfied $(++70.8 \%)$ or satisfied $(+26.8 \%)$, with only one not fully satisfied response (-2.4\%). In 3 out of 4 schools, a meeting between the alternanza contacts at the school and the University contacts to evaluate the projects/pathways and plan future activities had already taken place or was scheduled at the time of the survey. 


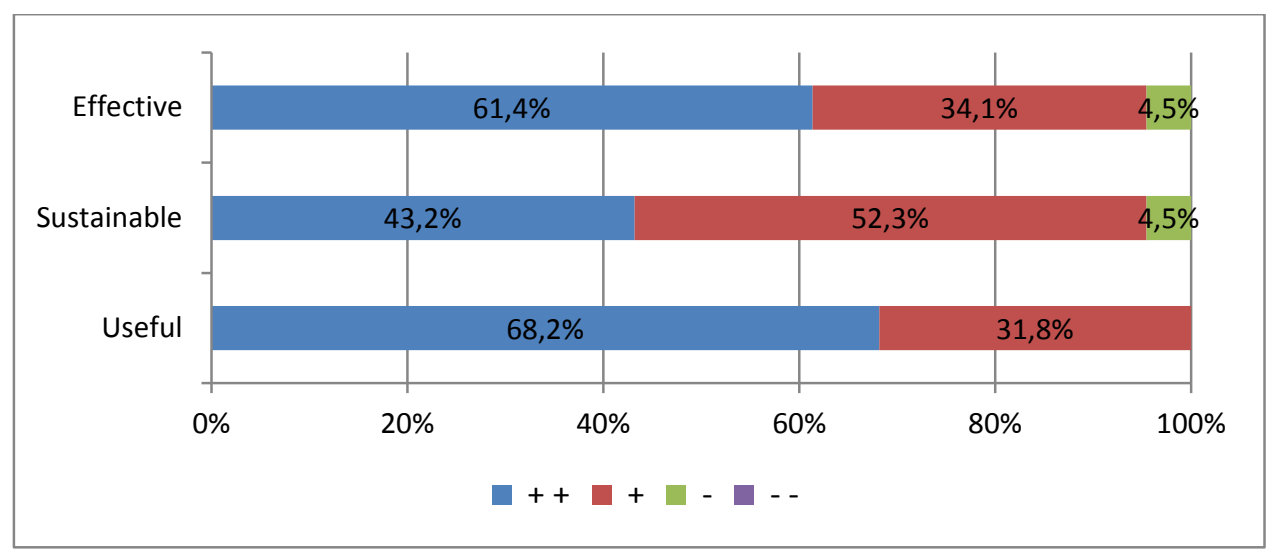

Figure 2. The co-designing approach.

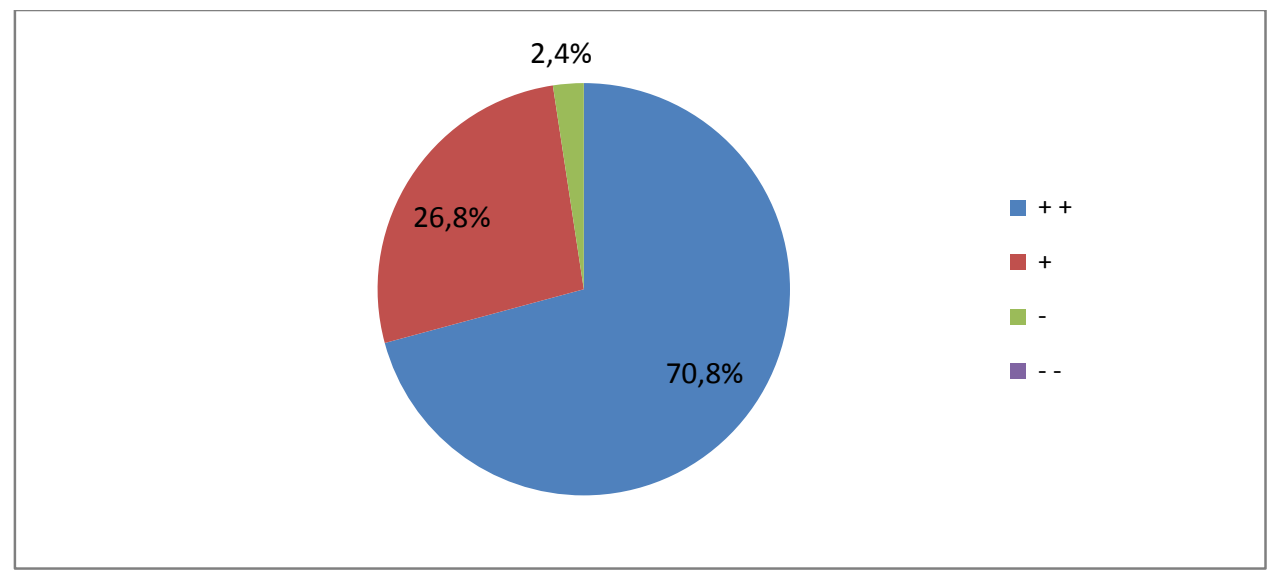

Figure 3. Student satisfaction

\section{Areas for development}

The alternanza offered by UCSC seems to correspond well with a pedagogical approach centred on the following: the central position of the individual, the integrated nature of knowledge and the cultural and educational importance of practical activity (Sandrone, 2016). Whilst the study confirms the satisfaction of the participating schools, from the perspective of ongoing improvement, a number of areas for development emerged in relation to evaluation in particular (Sandal, Smith \& Wangensteen, 2014). Indeed, this survey questioned the school contact teachers for the alternanza project and, consequently, the ideas expressed reflect only one point of view. In future years, it may be useful to investigate the points of view of all individuals concerned more closely: firstly, the students, who are acknowledged as competent individuals entitled to opinions on their 
educational experiences (Grion \& Cook-Sather, 2013), but also the company tutors i.e. the individuals (administrative and/or academic) who directly supported the students, to achieve a deeper and fuller understanding of the experiences and identify ways to continually improve them.

Beyond the experience itself, universities should consider alternanza a major topic for consideration, since it incorporates the three fundamental pillars of research, education and the third mission.

\section{References}

Akkerman, S.F., \& Bakker, A. (2012). Crossing boundaries between school and work during apprenticeships. Vocations and Learning, 5, 153-173.

Bertagna, G. (2013). Lavoro scuola apprendistato: idee per un rilancio dell'istruzione e della formazione. PROSPETTIVA EP, 26(3), 23-36.

Crivellari, C. (2018). La formazione dei docenti per la scuola dell'alternanza. FORMAZIONE \& INSEGNAMENTO. Rivista internazionale di Scienze dell'educazione e della formazione, 15(3), 203-212.

Cuppini, P. (2018). L'Alternanza Scuola-Lavoro nelle Marche. Scuola democratica, 9(1), 111-118.

Dalrymple, R., Kemp, C., \& Smith, P. (2014). Characterising Work-Based Learning as a Triadic Learning Endeavour. Journal of Further and Higher Education, 38(1), 75-89.

Fabbri, L., Melacarne, C., \& Allodola, V. F. (2015). Apprendere dai contesti di pratica situata: modelli didattici innovativi nell'alternanza scuola-lavoro. Educational reflective practices, 1 , 65-77.

Fedeli, M., \& Tino, C. (2018). Una ricerca qualitativa sull'Alternanza Scuola Lavoro. Riflessioni e Implicazioni per la didattica. FORMAZIONE \& INSEGNAMENTO. Rivista internazionale di Scienze dell'educazione e della formazione, 15(3), 213-224.

Flynn, M.C., Pillay, H., \& Watters, J. (2016). Industry-school partnerships: boundary crossing to enable school to work transitions. Journal of Education and Work, 29(3), 309-331.

Gentili, C. (2016). L'alternanza scuola-lavoro: paradigmi pedagogici e modelli didattici. Nuova secondaria, 33(10), 16-38.

Gibbs, P., \& Armsby, P. (2010). Higher Education Quality and Work-Based Learning: Two Concepts Not yet Fully Integrated. Quality in Higher Education, 16(2), 185-187.

Grion, V., \& Cook-Sather, A. (2013). Student Voice. Prospettive internazionali e pratiche emergenti in Italia. Milano: Guerini.

Loiodice, I., Ladogana, M., Colangelo, C., \& Dato, D. (2018). Alternanza scuola-lavoro all'università: costruire reti per il public engagement. In M. Rui (Ed.), Progress to work. Contesti, processi educativi e mediazioni tecnologiche (pp. 477-490). Genova: Genova University Press. 
Montalbetti, K. (2018). L’alternanza scuola-lavoro interpella l'università: Ricerca, Formazione e terza Missione. In S. Ulivieri (Ed.). Le emergenze educative della società contemporanea Progetti e proposte per il cambiamento (pp. 499-504). Brescia-Lecce: Pensa Multimedia.

Nicoli, D., \& Salatin, A. (Eds.) (2018). L'alternanza scuola-lavoro. Esempi di progetti fra classe, scuola e territorio. Trento: Erickson.

Sandal, A.K., Smith, K., \& Wangensteen, R. (2014). Vocational students experiences with assessment in workplace learning. Vocations and Learning, 7, 241-261.

Sandrone, D. G. (2016). Alternanza scuola lavoro. Un dispositivo da applicare o una strategia formativa? CQIA RIVISTA, 6(18), 8-15.

Sappa, V., Choy, S., \& Aprea, C. (2016). Stakeholders conceptions of connecting learning at different sites in two national VET systems. Journal of Vocational Education \& Training, 68(3), 283-301.

Schaap, H., Baartman, L., \& Bruijn, E. (2012). Students' learning processes during schoolbased learning and workplace learning in vocational education: a review. Vocations and Learning, 5(2), 99-117.

Sicurello, R. (2016). Potenzialità e sfide del modello di apprendimento in alternanza scuolalavoro. Lifelong Lifewide Learning, 12(28), 1-19.

Torre, E. M. (2016). Nuove competenze per l'insegnante di scuola secondaria di secondo grado: l’alternanza scuola-lavoro. Form@re, 16(2), 137-154.

Torre, E. M. (2017). Progettare e valutare percorsi di alternanza scuola-lavoro nella scuola secondaria di secondo grado: criticità e prospettive. Form@re, 17(3), 262-276.

Vecchiarelli, M. (2015). Alternanza scuola-lavoro: Analisi di percorsi curricolari nazionali e transnazionali. Roma: Edizioni Nuova Cultura.

Wesselink, R., De Jong, C., \& Biemans, H.J.A. (2010). Aspects of competence-based education as footholds to improve the connectivity between learning in school and in the workplace. Vocations and Learning, 3, 19-38. 